\title{
Utilizando o Youtube para Ensino da Linguagem C em Cursos de Engenharia
}

\author{
Leandro de C. Santos ${ }^{1}$, Samira S. da Silva ${ }^{2}$, Sincler P. de Meireles ${ }^{1}$ \\ ${ }^{1}$ Departamento de Ciências Exatas- Universidade do Estado de Minas Gerais \\ Av. Brasília, 1304 - Bau, João Monlevade - MG, Brasil - 35930-314 \\ ${ }^{2}$ Engenharia da Computação- Universidade do Estado de Minas Gerais \\ Av. Paraná, 3001 - Jardim Belvedere I, Divinópolis - MG, Brasil - 35501-170 \\ \{leandrocastro19081999@gmail.com, samirapgti@gmail.com, \\ professorsincler@gmail.br
}

\begin{abstract}
This article describes the use of a methodology for teaching programming based on the use of videos produced and posted on YouTube. Analyzing the results, it is possible to conclude that the creation of custommade videos can contribute to the teaching-learning process of computer programming in Engineering courses. In addition, YouTube proved to be an interesting streaming tool for facilitating class feedback and also for offering metrics that indicate the acceptance of the videos.
\end{abstract}

Resumo. Este artigo descreve o uso de uma metodologia para ensino de programação baseada no uso de vídeos produzidos e postados no Youtube. A partir dos resultados conclui-se que a produção de vídeos sob medida pode contribuir significantemente para o processo ensino-aprendizagem de programação de computadores em cursos de Engenharia. Além disso, o Youtube se mostrou uma ferramenta de streaming bastante interessante por facilitar o feedback das aulas e também por oferecer métricas que indicam a recepção dos vídeos.

\section{Introdução}

A disciplina Fundamentos da Computação, ministrada no segundo período dos quatro cursos de Engenharia da Universidade do Estado de Minas Gerais (UEMG) de João Monlevade, tem como principal propósito promover conhecimentos e competências necessária para que os alunos sejam capazes de conceber desde programas simples, até códigos mais complexos escritos em linguagem C. Espera-se que provido desse conhecimento, o aluno seja capazes de resolver problemas de diversas naturezas, como matemáticos e físicos, comuns às diversas engenharias e a outras áreas do conhecimento. Apesar de sua importância, o ensino e aprendizagem de programação constituem um enorme desafio pra alunos e professores, demonstrado pelos elevados níveis de insucesso nas disciplinas introdutórias de programação dos cursos de Engenharia, resultando muitas vezes em evasão (BENNEDSEN, 2019; AURELIANO, 2020).

Para contornar os problemas referentes ao ensino e aprendizagem envolvendo a programação de computadores, é necessário o levantamento de estratégias e metodologias que facilitem a transmissão desses conhecimentos. Atualmente, como 
principal tendência, temos o uso de recursos tecnológicos. Para Filho (2010), a incorporação das novas Tecnologias da Informação e Comunicação (TICs) implica em novas práticas docentes, as quais necessitam de processos de formação e acompanhamento que garantam sua adequada qualidade educativa. Segundo Dos Santos e Costa (2006), esses recursos não devem se apenas utilizados no modo como se encontram, mas devem ser acompanhados de uma preparação prévia para o uso. Esses autores ainda ressaltam que se torna necessária uma expressiva pesquisa antes da utilização.

Santos e Ribeiro (2018) chamam a atenção para as possibilidades da educação utilizando TICs, de modo a quebrar esta dinâmica passiva, uma vez que se utilizam de meios e dispositivos diversos, tanto de forma presencial, quanto à distância, e que em grande parte estão alinhados com os interesses dos educandos. Dentre as diversas TICs, destaca-se os vídeos para o ensino. A ideia de utilizar vídeos e filmes na educação não é nova. Teixeira (1963) já destacava o potencial de tal recurso. O vídeo é capaz de estimular diversos sentidos, desenvolvendo a imaginação, que por sua vez está interligada à afetividade, gerando uma resposta sensível nos receptores [Morán, 1995].

Especialmente nos últimos anos, a produção de vídeos se tornou cada vez mais fácil. As opções de criação são as mais diversas. As técnicas de gravação e edição se tornaram mais acessíveis através da Internet. A criação de vídeos com qualidade, seja com câmeras de vídeo sofisticadas ou até mesmo com câmeras de aparelhos celulares e tablets, se tornou uma tarefa fácil. Segundo Borba e Oechsler (2018), além da redução do custo e facilidade no uso de equipamentos que permitem a gravação de áudio e vídeo, a Internet rápida também teve papel fundamental na popularização desse recurso. No mesmo trabalho, Borba e Oechsler concluem que a temática "vídeo para ensino" apresenta um campo vasto de estudos, seja com foco na gravação de aulas, no vídeo como material didático, ou com foco voltado para a produção de vídeos.

Como advertido por Morán (1995), o vídeo por si só não é capaz de solucionar todos os problemas do processo ensino-aprendizagem e pouco modifica a relação pedagógica. Entretanto, quando criadas as condições adequadas, mediante uma metodologia bem acertada, esse recurso pode atingir resultados positivos. Diante desse cenário, buscando utilizar as tecnologias e recursos disponíveis, neste trabalho foi realizado o desenvolvimento e avaliação do uso de vídeos como suporte fora de sala de aula, através de um canal no YouTube ${ }^{1}$, para o ensino de Programação para cursos de Engenharia .

\section{Metodologia}

O experimento aqui relatado foi realizado nas turmas da disciplina "Fundamentos da Computação" ministradas aos cursos de Engenharia da UEMG - João Monlevade no ano de 2019. A primeira etapa na execução do projeto consiste na produção dos vídeos. Com o auxílio do monitor da disciplina, foram levantados os problemas mais comuns enfrentados pelos alunos na disciplina. Realizada a identificação dos problemas, o conteúdo da disciplina foi dividido em temas e foram escolhidos os pontos que seriam abordados nos vídeos. Após a definição dos problemas enfrentados pelos alunos em sala de aula, foi elaborado um script simplificado para cada um dos vídeos contemplando

\footnotetext{
${ }^{1}$ https://www.youtube.com/channel/UCJEr2CuE3SuVpYhVm-wvLTQ
} 
tópicos da disciplina. O roteiro foi revisado, sendo observado não somente o conteúdo mas também a linguagem utilizada. A partir da aprovação do script, foram gravadas e editadas as cenas necessárias, formando assim o material final.

Mediante a dificuldades técnicas para gravar as videoaulas utilizando um ambiente real de sala de aula, foi utilizado o estilo de vídeo onde se grava a tela do computador. Isso eliminaria a necessidade de preocupações com aquisição de cenas e consequentemente de preocupações com iluminação, enquadramento, figurino, entre outros aspectos técnicos. Buscando uma melhor recepção dos espectadores, decidiu-se por utilizar um roteiro simplificado, onde o narrador poderia improvisar e ser mais informal nas explicações. Na Figura 1 temos uma captura de tela de um dos vídeos produzidos. Esperava-se também que ao não utilizar cenas que exibem um professor ou um outro ator, fosse possível remeter ao aluno a mesma sensação da tela do computador.

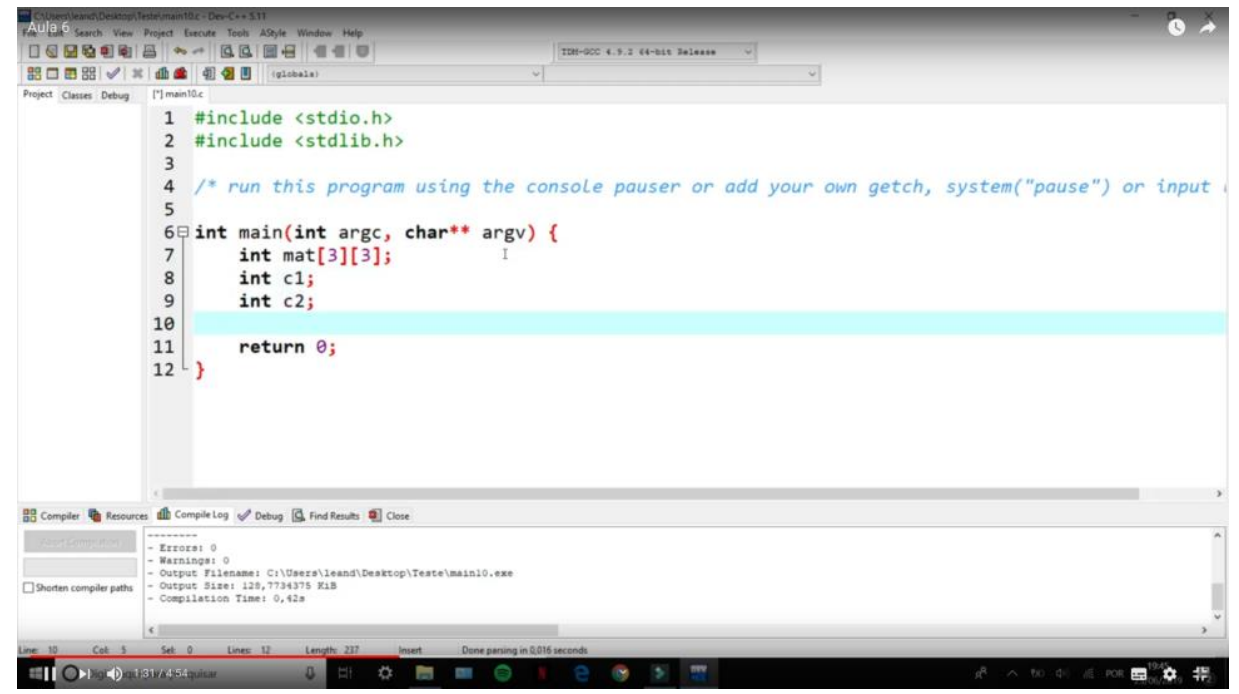

Figura 1. Captura de tela da exibição de um vídeo utilizado no experimento.

Para obter melhores resultados, inicialmente somente as duas primeiras aulas foram liberadas aos alunos e aguardado o retorno dos mesmos. Assim, as demais aulas foram gravadas levando em consideração as sugestões coletadas, tanto em sala de aula quanto através das impressões fornecidas em comentários e marcações. Entre essas sugestões estão mudanças na linguagem utilizada pelo aluno que narrou os vídeos. Uma vez os vídeos produzidos, estes passaram a ser disponibilizados antes que o tema fosse trabalhado em sala de aula adotando o modelo de sala de aula invertida.

Para a avaliação do desempenho da metodologia, foram utilizados os resultados obtidos nas duas avaliações aplicadas durante o semestre e também a nota final que contabiliza todas as atividades, indicando a aprovação ou reprovação na disciplina. Além disso foi observado e comparado o número de alunos que evadiram da disciplina tanto na turma experimento quanto na turma controle.

\section{Resultados}

Os resultados foram obtidos para a turma controle (sem utilização dos vídeos) e para a turma experimento (com o auxílio dos vídeos) e podem ser vistos através dos gráficos da Figura 2. Por simplificação, todas as colunas que fazem menção à turma controle 
aparecem em azul e todas que fazem menção à turma experimento aparecem na cor laranja. Em todos os gráficos os valores são expressos em percentuais.

No canto superior esquerdo, é apresentada a média das notas na primeira e na segunda avaliação de ambas as turmas. Na primeira avaliação a turma controle alcançou uma média de $31,05 \%$ da nota total, enquanto que a turma experimento obteve uma média de $57,89 \%$, sendo o erro inferior à $8 \%$. Isso demonstra uma melhora significativa nas notas pela introdução da metodologia proposta.

Ainda no gráfico do canto superior esquerdo, observa-se que na segunda prova se manteve o melhor desempenho da turma experimento exibindo uma média de $62 \%$, enquanto a turma controle $57,89 \%$. No entanto, as notas apresentaram uma maior variação levando à um erro para as medidas de $12 \%$ e $7 \%$, respectivamente. No gráfico do canto superior direito, é possível observar um aumento no percentual de aprovados e uma redução do número de reprovados por falta, mostrando não somente a efetividade da metodologia proposta mas também que a mesma manteve os alunos engajados devido à redução na evasão.
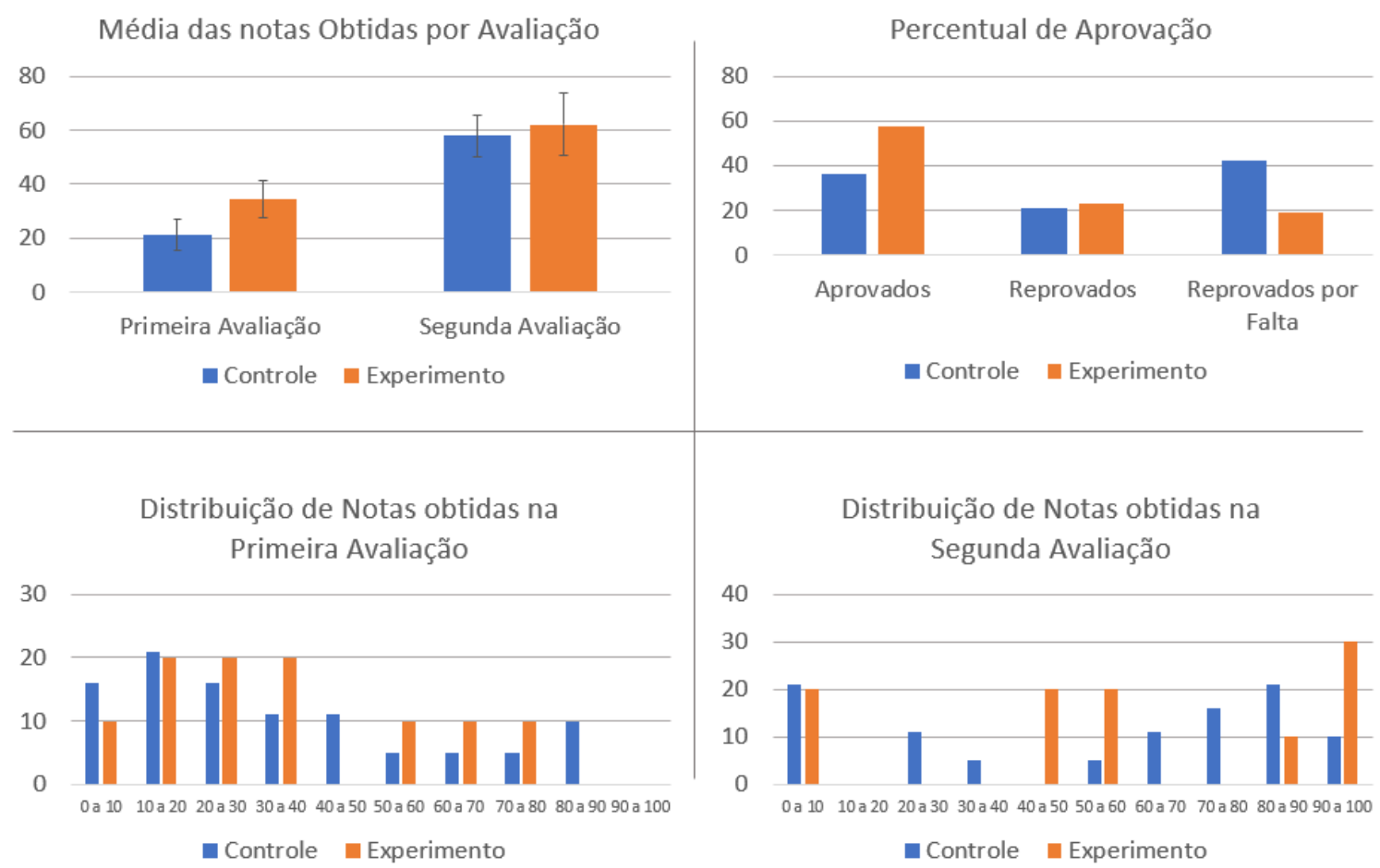

Figura 2. Gráficos comparativos entre turma Experimento e Controle.

Na parte inferior da figura, temos a distribuição das notas obtidas na primeira e segunda avaliação, respectivamente. Observa-se um leve deslocamento da tendência na primeira avaliação, onde na turma experimento é observada uma redução do percentual de alunos com notas abaixo de $10 \%$ e o surgimento de alunos com notas acima de $80 \%$. Já na segunda avaliação, manteve-se um valor próximo aos que obtiveram entre $0 \mathrm{e}$ $10 \%$. Entretanto, uma grande parcela, quase um terço da turma experimento, obteve notas entre $90 \%$ e $100 \%$. Isso se deve pela redução do número de alunos que tiraram notas abaixo de $40 \%$ e também pela promoção dos alunos entre $40 \%$ e $90 \%$ para notas acima de $90 \%$. 


\section{Conclusões}

Apesar de existirem diversos vídeos sobre programação em linguagem C, os alunos geralmente apresentam muita resistência em procurá-los numa abordagem convencional de ensino. Entretanto, utilizando o modelo de sala de aula invertida e produzindo vídeos sob demanda foi observado um maior interesse no conteúdo ministrado por parte dos mesmos. Além dos vídeos consistirem de uma linguagem melhor adaptada, os alunos podiam rever os conteúdos e exemplos.

Outro importante aspecto que ajuda a explicar o melhor resultado da turma experimento é a otimização do tempo dentro de sala de aula. O tempo dentro de sala de aula dedicado à exposição do conteúdo foi poupado pelo uso de sala de aula invertida, e assim os alunos conseguiram realizar uma quantidade muitos maior de atividades práticas. Esse tempo também pôde ser aproveitado para sanar dúvidas, possibilitando também ao professor realizar um atendimento mais próximo de cada um dos alunos.

Mediante aos resultados obtidos, pode-se concluir que a metodologia utilizada é de grande valia para o ensino de programação em linguagem $\mathrm{C}$ para cursos de Engenharia.

\section{Agradecimentos}

Agradecemos à UEMG- Campus João Monlevade pelo aval na realização da pesquisa e também ao Programa Institucional de Apoio à Pesquisa da UEMG - PAPq / UEMG pela concessão de uma Bolsa de Iniciação Científica.

\section{Referências}

Aureliano, V. C. O.; Tedesco, P. C. de A. R.; Giraffa, L. M. M. Desafios e oportunidades aos processos de ensino e de aprendizagem de programação para iniciantes. In: Anais do XXIV Workshop sobre Educação em Computação. SBC, 2020. p. 71-80.

Bennedsen, Jens e Caspersen, Michael E. Failure rates in introductory programming: 12 years later. ACM Inroads, v. 10, n. 2, p. 30-36, 2019.

Borba, M; Oechsler, V. Tecnologias na educação: o uso dos vídeos em sala de aula. Revista Brasileira de Ensino de Ciência e Tecnologia. 2018. V.11. n. 2.

Dos Santos, R. P. e Costa, H. A. X. Análise de Metodologias e Ambientes de Ensino para Algoritmos, Estruturas de Dados e Programação aos iniciantes em Computação e Informática. INFOCOMP, [S.1.], v. 5, n. 1, p. 41-50, mar. 2006.

Filho, V. H de O. As Novas Tecnologias E A Mediação Do Processo Ensino Aprendizagem Na Escola. Anais do VI Encontro de Pesquisa em Educação, Teresina, 01 a 03 de dezembro de 2010.

Morán, J. O vídeo na sala de aula. Comunicação \& Educação, n. 2, p. 27-35, 30 abr. 1995.

Santos, L. R. dos e Ribeiro, A. G. Hipermídia no ensino médio técnico como estratégia de aprendizagem. Temática. Ano XIV, n. 10. Outubro, 2018.

Teixeira, A. Mestres de amanhã. Revista Brasileira de Estudos Pedagógicos, 92. v. 40, p. 10-19, 1963. 